\title{
ERRATUM
}

\section{Reversible Catastrophic Fat Embolism: A Case Report}

\section{Kethy Jules-Elysee • Thomas P. Sculco}

Published online: 13 September 2006

(C) Hospital for Special Surgery 2006

The sentence in the beginning of the Discussion section was published incorrectly. It should have read: This case is very interesting because the patient had an uneventful and full recovery postoperatively in spite of evidence of a nearfatal fat embolism syndrome (FES) occurring intraoperatively.

Article appears in HSS Journal, Vol. 2, No. 1, pp. 59-61. http://dx.doi.org/10.1007/s11420-005-0141-z.

K. Jules-Elysee $(\square)$

Department of Anesthesiology,

Hospital for Special Surgery,

535 East 70th Street, New York, NY 10021, USA

e-mail: JulesElyseeK@hss.edu

\section{T. P. Sculco}

Department of Orthopaedic Surgery,

Hospital for Special Surgery,

535 East 70th Street, New York, NY 10021, USA 